\title{
The Existing Questions and Strategies Analysis of the New Times College English Teaching
}

\author{
LIU Dehua \\ College of electronic commerce, Jiangxi College of Engineering, Jiangxi 338000,China \\ liudehuajx@126.com
}

\begin{abstract}
Keywords: College, English, education teaching, questions, strategies
Abstract. With the development of domestic social and economic progress, our country keeps on advancing in the international community and keeps more closely contact with other countries in the world. Working on the corresponding English education teaching work positively is obviously very important. For a long time, the social all walks of life and the national department of education focus on the situation of English education in domestic universities. A series of detailed measures put forward by the ministry of education for the purpose of enhancing the teaching quality of domestic institutions of higher learning occupy an important position for the reform of college English teaching. This article analyzes from the current existing problems in the teaching of college English education, and then put forward the corresponding teaching reform of college English education in view of the reality and the existing problems.
\end{abstract}

\section{The teaching orientation of the college English education}

In recent years, as the rising status in the international community, China has an increasingly closely link with the outside world. Under the new social environment and historical background, English as a communication tool has become the highest international communication language in the world and has increased highlights the importance of a stronger international competitiveness level. Higher education, for the purpose of cultivating to meet the needs of many fields such as economic development needs, social culture, the development of science and technology and for the purpose of high-quality comprehensive talents having the international competitiveness demands to give English teaching enough attention trying to improve the teaching idea and teaching method, improve education effect. In the new era, college English education teaching reform is necessary.

The concept and professional English college English contains different meanings, generally refers to the school's public English courses for non-English major students. Different from learning English major students, the rest of the students to learn English, time shorter, but learners scope is bigger. Compared with other education discipline in colleges and universities, college English teaching show some differences. Under the new era, English education has cultural education, language education, quality-oriented education characteristic determines its in curriculum system in colleges and universities, the important position of the communication among countries is to promote our country and the rest of the world, science and technology is an effective means of cultural exchange, to improve national occupy a position in the international affairs and international development has important significance. Domestic universities to carry out the education mode and adopted in English teaching high school English teaching has more obvious different. Secondary school English teaching, generally contain in English grammar, sentence patterns, such as basic knowledge teaching, is the foundation of the college English education. College English education teaching system is shown in chart1. 


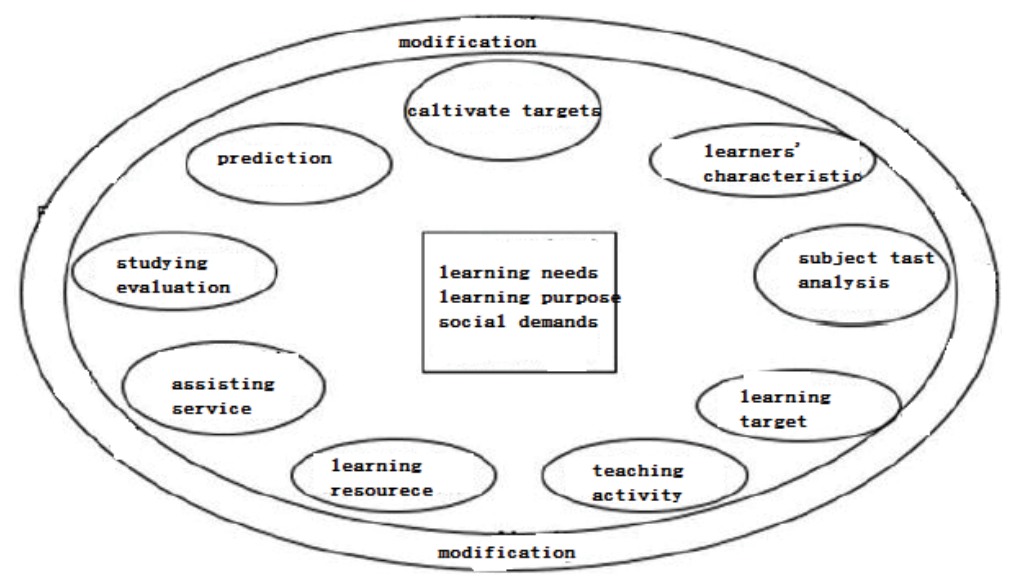

Chart 1: the flowchart of the college English teaching system

But we should be clear that the domestic secondary school English teaching generally belongs to the category of exam-oriented education, causes most of the students have obvious lack of the English using ability and language ability, also makes the most of the students admitted to the university with very poor ability of learning English, the attitude of English teaching was to deal with it, lack of correct cognition of the English course in the important position of university curriculum system. English teachers in colleges and universities also accustomed to this kind of phenomenon, their education work often holds a perfunctory attitude to deal with. In recent years, colleges and universities constantly expand the scale of enrollment leading to bigger ability level difference of college students' English level and language, the overall level of English is declining. Many students can't meet the learning requirements in English directly affecting the effect of English teaching.

\section{The existing questions in the current college English teaching}

Lack of direct orientation. Many factors affecting the effects of college English education teaching work, the lack of a clear cognition occupies the main position for English teaching. Most of the institutions of higher learning in college English teaching often set to encourage students be able to pass the English test band 4 and band 6 as the purpose and ignore the students' English using ability, the cultivation of the master level, unable to reach national institutions of higher learning English education teaching purpose. The actual situation is that the most domestic colleges did not set a clear positioning of the English education, lacking its subordinate professional English education or the cognition of public English education category. This kind of situation will directly affect the colleges and universities to carry out the work of college English education without any guarantee to the teaching level and teaching quality.

The effect of the market. Along with the continuous expansion of enrollment in recent years in domestic institutions as well as higher learning development, the economic benefits of teaching material and test market existed also gradually highlights. The economic profits of teaching material market leads to unit links between interests of the press, English textbook writers, college English test, and form a sense of monopoly model. Even the teachers engaged in college English education in colleges and universities also become one of the means to obtain economic profits. And the social all walks of life have different criticism attitude to national public English test band 4 and band 6 . Market situation also has bad effect on college English education work in colleges and universities.

The lack of corresponding policies. The relevant departments of domestic competent education work of for different period of the English education teaching work, to develop a series of corresponding policies and measures. Relevant policy formulation and implementation of the development of the domestic English education teaching work has important guiding significance. However, make and implement the domestic English education teaching related in a variety of program planning and policy, tend to lack a long-term and scientific. For some details in English education teaching, lack of corresponding elaboration and guidance. The emergence of this situation, also for universities to carry out English teaching has some impact. 


\subsection{Biased teaching theory and teaching idea}

Since the reform and opening up, China's role in international affairs as well as rising, plays a more and more important role. With the augmentation of the state international influence, the abroad large Numbers of teaching theory to the introduction of domestic, many education workers in this case the lack of clear, lead to shortcomings existing in the teaching theory abroad also entered the education field. Domestic traditional education method, although there are some problems, but positive factors still occupied the main position. As composed of many ethnic groups in developing countries, foreign teaching theory can be applied in the domestic education teaching work, application of the outcome, all need linguist, rigorous validation of education experts and other professionals.

College English teachers' training. Among the teachers engaged in the work of English education in domestic colleges and universities teachers, the majority are graduated from colleges in the English department. They attempt to pay more attention to the cultivation of language skills during the school term, but ignore the comprehensive quality of ascension, especially to have professional knowledge in the field of talent is scarce, which creates a mismatch between college English teachers and non-English major students phenomenon. When facing this phenomenon, although the domestic institutions of higher learning has appeared to directly allocate to the required English teachers in the department, mainly responsible for the hospital department student teaching measures, the teaching effect obtained did not reach the expected effect. The college English teachers at the faculty need to improve their level, but not all of the colleges and universities can provide English teachers with the ability of learning opportunities again for teachers to provide strong support for scientific research and teaching work.

\section{Reform measures to the new time college English teaching}

To promote college English education work effect, first is to education purpose has a clear understanding of the college English teaching. Under the background of new era, the English education should cultivate students' English using ability; enable students to have the ability to work through English to complete a certain field. English education complies with the track of development of the individual as well as the development and change of social environment. In the view of the country's talents and the society as a research starting point, the college English education should cultivate students' effective communication through English and the ability to complete the advanced experience, learning advanced science and technology of the west, spread and popularization the traditional Chinese culture to the world.

During college English education teaching process, we also need to actively develop reasonable language policy in order to better advance the actual education teaching work with scientific guidance. Specifically, in the process of establishing a variety of language policy, language shall be based on the number of teachers working in this kind of language education teachers have the professional quality and teaching ability, as well as the basis of learning the language of the students have social scientific and detailed investigation and analysis for the demand of the language. A summary of the investigation, it is concluded that the specific findings, and set the results as a standard to make the corresponding policy. Good language policy can provide guarantee for national political promotion and economic development, and give attention to two or more things to learn a language environment and the size of the education resources, and other factors, and combined with the actual situation of the state and society to develop. For English language education policy in all aspects of the planning and research to offer help.

As the most use language in the world, English has been used in our country for a long time. With the country's social development and economic progress, education career has also been put more attention. The factors related to English education teaching also get rapid development and a lot of changes accordingly. National education theory argues that the Chinese traditional theory plays a main role in many aspects, such as in promoting students' physical and mental health development, forming a good personality, improve moral standard, while western doctrines can cultivate students' ability of human behavior, so we should outstanding Chinese teaching factors along with the 
combination with the western teaching advantages, common to improve the levels of national education. As a result, people engaged in English education must be able to find the advantages and problems existing in the national English education teaching, selective absorption of the western education strengths, but cannot choose the western education way blind.

Professional teacher belongs to a generalized concept, which generally includes external promote teacher professional development and the process of teachers' professionalism process of ascension. Teachers' professional development in order to enhance teachers' teaching ability has the professional knowledge and the education concept of the inherent factors promoted to study of target, to enhance the education effect, increase teaching efficiency and teaching level, to further increase for the purpose of university education workers professional quality. As a common open tutorials, college English as advanced education to establish the course system of occupy the important position. Engaged in the teaching of college English education workers, first of all, they must have rich knowledge of teaching thus they can ensure the promotion the teaching level and teaching work smoothly. Along with the social development and progress of the Times, knowledge explosion era has come. Facing the new era, English teachers should have positive attitude of keeping pace with The Times, so as to meet the requirements of English teaching for teachers. To improve the university faculty, further enhance the teachers' professional quality and professional development, promote teachers' professional level, developing a detailed evaluation standard to increase the construction of normal colleges and universities. The English education majors and have been engaged in the work of the college English education teachers for dynamic assessment. In the following way, guarantee the work carried out smoothly.

\section{Summary}

This paper discusses the existing problems in the process a new form of teaching of college English education to be carried out in the new era. And it is concluded that such a problem has harm and adverse effects on realizing the goal of college English education teaching, especially when the college students' English ability can't meet the needs of social progress, economic development. With close combination with the actual situation, it gives a detailed argument for such a serious problem, and provide scientific and reasonable measures for specific conditions. The paper will inevitably has some drawbacks limited to the author's own knowledge level. It will serve as a modest spur to induce other papers and get more support from outside and push relevant issues more argument in order to provide help for solving the problem as soon as possible.

\section{References}

[1] Li Huatian. PBL - BTC multidimensional English reading education teaching research- set general education course "English creative reading" for example [J]. Journal of teacher education forum, 2015, 28 (11) : 66-69

[2] Liu Hua. Some problems and countermeasures in the development of Chinese college English teaching [J]. Journal of Heilongjiang institute of education, 2014 (3) : 159-160.

[3] Zhang Yan, Xu Zhujun. Problems and countermeasures in the time of transition of college English curriculum-based on the concept of interdisciplinary talents thinking [J]. Journal of South China university of technology (social science edition), 2015 (2) : 124-128.

[4] Kuang Xilin. Deep problems and rational countermeasures study of college English teaching [J]. Journal of Inner Mongolia normal university (education sciences), 2013, 26 (5) : 129-132.

[5] Bai Juan. Analysis of the existing problems in the college English teaching in higher vocational colleges and countermeasures [J]. Journal of exam, 2015, (83) : 91. 